\title{
Patent Ductus Arteriosus Device Closure with Venous Only Access - A Retrospective Analysis
}

\author{
Vinayakumar Deshabandu ${ }^{1}$, Sajeer Kalathingathodika², Suresh Shivakumar ${ }^{3}$ \\ 1,2,3 Department of Cardiology, Government Medical College, Kozhikode, Kerala, India.
}

\section{ABSTRACT}

\section{BACKGROUND}

Patent ductus arteriosus (PDA) can be closed percutaneously by a device with and without arterial access. The conventional technique involves a femoral arterial as well as femoral venous access for closure. Here we discuss our institutional data in closing the PDA without arterial access. We wanted to study retrospectively the feasibility and outcome of PDA device closure in young children via femoral vein without femoral arterial access.

\section{METHODS}

From November 2011 to March 2018, 228 patients were evaluated clinically and echocardiographically for PDA device closure and 201(88 \%) were found suitable. These 201 patients who underwent transcatheter PDA closure via femoral venous access were included in the study. Detailed 2D echocardiography and Doppler assessment were performed before the procedure. During transcatheter closure, fluoroscopic injections were done in two views by the catheter stationed at the PDA ampulla into the descending thoracic aorta. All PDAs were closed by Amplatzer duct occluder-I (ADO1 device). The detailed echocardiographic assessment was performed in each case before releasing the device from the delivery cable and at 5 minutes and 10-minute intervals thereafter till there was no significant flow across the duct. Echocardiography was performed immediately after the device deployment, at 12 hours and 24 hours.

\section{RESULTS}

Total 201 patients underwent PDA device closure via femoral venous access. The mean age was 1 year and 6 months (range 6 months to 47 years). The mean weight was $15 \mathrm{~kg}$ (range 5 to $66 \mathrm{~kg}$ ). Females constituted $67.6 \%$ (136 patients). 9 patients (4.4\%) had Down syndrome and 12 (5.9\%) had additional cardiac problems. In 108 patients, $6 \times 8$ size device was placed (53.7\%), in 44 patients, $4 \times 6$ size device (21.9\%), 30 patients with 8x10 size devices (14.9\%) and a few patients with other sizes. Two patients developed immediate complications which were addressed appropriately.

\section{CONCLUSIONS}

PDAs can be safely closed without arterial access. Operators' skill and experience determine a successful outcome. Patient selection and detailed assessment of PDA before the procedure is of paramount importance. This transcatheter closure without arterial access makes the procedure simpler with low morbidity and complications.

\section{KEY WORDS}

Congenital Heart Disease, Patent Ductus Arteriosus, Device Closure, Amplatzer Duct Occluder
Corresponding Author: Dr. Sajeer Kalathingathodika, Assistant Professor, Department of Cardiology, Government Medical College, Kozhikode, Kerala, India. E-mail: drsajeerkt@gmail.com

DOI: $10.14260 /$ jemds/2022/10

How to Cite This Article: Deshabandu V, Kalathingathodika S, Shivakumar S. Patent Ductus Arteriosus device closure with venous only access - a retrospective analysis. J Evolution Med Dent Sci 2022;11(01):50-54, DOI: 10.14260/jemds/2022/10

Submission 20-12-2021,

Peer Review 27-12-2021,

Acceptance 19-01-2022,

Published 24-01-2022.

Copyright (C) 2022 Vinayakumar Deshabandu et al. This is an open access article distributed under Creative Commons Attribution License [Attribution 4.0 International (CC BY 4.0)] 


\section{BACKGROUND}

PDA is a common congenital heart disease with a reported occurrence of 0.87 per thousand live births and constitutes 6 $11 \%$ of all congenital heart diseases. ${ }^{1-2}$ First transcatheter method was developed by Porstman et al. in the late 1960s, later by Rashkind et al. in the late 1970 s. $^{3}$ Since then the technique has successfully replaced surgical PDA ligation as the primary option in all age groups. The technique has evolved and has been better defined in technique as well as device design. FDA approved Gianturco coil, Gianturco- Grifka vascular occlusion device and Amplatzer duct occluder for PDA device closure.

The symptoms and clinical features of PDA vary considerably with the quantity of pulmonary blood flow, the pulmonary vasculature resistance, and the presence of coexistent cardiac anomalies. ${ }^{4}$ The evolution and advances in echocardiography have helped a lot in the diagnosis of PDA, determining the size of the duct and its hemodynamic implications non-invasively with a high degree of accuracy. Echocardiography has aided the interventionist in modifying the technique of transcatheter closure of PDA in several ways. The presence and size of the PDA can be measured accurately using echocardiography before closing the defect. Doppler techniques are used to estimate the pulmonary artery pressure. $^{5}$ All PDAs that are apparent by physical examination should be closed. Indication to close incidentally detected small ducts during echocardiography remains controversial. ${ }^{6}$ Several devices are available for effective percutaneous closure of PDA.

Initially, transcatheter PDA closure was done using single or multiple embolizations and was attempted successfully both by antegrade as well as retrograde approach.7-8 In 2003, the Amplatzer Duct Occluder (ADO) became the first FDA approved device for PDA closure. ${ }^{9}$ The techniques for PDA device closure varies depending on the operator and the skill. PDA device closure can be done through right femoral vein access. Femoral arterial access is an integral part of the technique for angiographically determining the size of the duct, size of the ampulla, providing a landmark during closure and for checking angiograms to assess the adequacy of closure. Arterial access adds to the morbidity, prolongs procedure and fluoroscopy times, needs additional expert wound care and has a small but definite added risk of arterial injury, bleeding, arterial thrombosis, lower limb ischemia and need for enhanced use of heparin. Right femoral artery access is taken for angiogram during device deployment. A few authorities have come out with their experience in performing transcatheter closure of PDA without an arterial line. Angiography may be obtained from the venous side by passing an antegrade wire across the duct and exchanging the catheter for the appropriate size. We are reviewing our experience in closing the PDA without arterial access in a larger cohort and that too across a broader age range with some technical differences from the previous series. ${ }^{10}$

\section{Objectives}

To study retrospectively the feasibility and outcome of PDA device closure in young children via femoral vein without femoral arterial access.

\section{METHODS}

This is a retrospective study from November 2011 to March 2018 comprising an analysis of all patients who underwent percutaneous PDA device closure during this period. After an initial experience with a large number of patients using the conventional technique with combined femoral arterial and venous accesses and using single-coil, multiple coils and ADO devices, we resorted to the deployment of PDA devices in suitable cases using femoral venous access only. Device closure was carried out for all clinically significant PDA. Detailed echocardiographic assessment was performed on all cases. Assessment included the evaluation of the PDA size, PDA type, PDA ampulla, assessment of pulmonary arteries and aortic arch. PDA shunt and PA pressure were assessed by echocardiographic Doppler. Cases were carefully selected for closure without an arterial line following strict exclusion criteria as below

1. Improper echocardiographic delineation of the PDA and aortic arch.

2. Large PDA with pulmonary hypertension for which diagnostic hemodynamic assessment was needed before PDA device closure.

3. Infants with large ducts - require larger devices which can lead to obstruction of descending aorta.

4. PDA without a good ampulla prevents the use of the ADO 1 design device.

5. Recanalized ducts following surgical closure.

6. Patients with other cardiac lesions requiring cardiac intervention

Cross over to a hybrid approach was decided as the default strategy if,

1. Contrast opacification on injection into the duct ampulla from the venous side was insufficient to delineate the duct.

2. There was difficulty in securing a stable device deployment without major vascular compromise.

3. The device seemed to be of inappropriate size on attempted deployment.

4. Device dislodgment occured requiring a snare assisted retrieval.

In all cases, written informed consent from parents were taken. Device closure was done under general anaesthesia in younger children and infants. Local anaesthesia was used in older children and adults. Blood pressure and heart rate were closely monitored. Heparin 50 unit/kg bolus was given before the procedure after right femoral vein access. This study was approved by the institute's research and ethical committees.

\section{Echocardiographic Assessment of PDA}

Detailed pre-procedure echocardiographic assessments of all cases were done using Philip's EPIC 7 and Philip's HD 11 XE echocardiography system, Andover, MA, USA by the primary operator. 2-dimensional echo evaluations were done as per the standard protocol. PDA was visualized in high PSAX view. Measurement of the PDA opening into the pulmonary artery was done in multiple cardiac cycles and the largest measurement was accepted. The ampulla was visualized and measured in suprasternal echo view and also assessment of 
the aortic arch for any coarctation or arch anomaly was done. Doppler assessment of the duct flow in the main and pulmonary artery branches and the descending thoracic aorta was estimated and any flow acceleration was noted. The device size was provisionally decided as $2 \mathrm{~mm}$ larger than the measured duct size.

\section{Duct Closure}

As previously decided cases were selected for a venous line, only approach was prepared under anaesthesia, femoral vein accessed using a micropuncture needle for paediatric cases and a standard puncture needle for adults. In cases where an inadvertent femoral arterial puncture occurred, an appropriate guidewire was inserted and retained till the procedure was over. An arterial sheath was not inserted. PDA was crossed from the venous side using a straight tipped 0.032-inch Terumo wire. (Terumo corp. Tokyo, Japan) through a 5F/6F Multipurpose angiographic catheter (MPA) (cook medical Inc, Bloomington, IN). The catheter tip was parked in the descending thoracic aorta just beyond the PDA ampulla and the guidewire was removed. A $10 \mathrm{ml}$ luer lock syringe loaded with contrast was used for injection in all cases. 3-5 $\mathrm{ml}$ of contrast was injected by hand in infants and children and 5-8 $\mathrm{ml}$ in adults. Angiography was done in the left lateral projection in all cases and left anterior oblique (LAO) projection when further delineation was required. Injection into the ampulla causes a contrast spillage through the duct into the pulmonary artery in all cases causing adequate opacification to assess the size of the PDA. In cases where the catheter recoil on injection prevented a proper visualization, a "Y connector" used for coronary angioplasty was connected to the catheter and a 0.014-inch coronary guidewire was passed through the catheter and parked in the descending aorta. Hand injection of contrast was done through the sidearm of the $\mathrm{Y}$ connector. This helped to prevent catheter recoil and obtain a good quality angiogram. Relation of tracheal air translucency with the duct ampulla was noted in the lateral view and kept as an angiographic landmark for positioning the aortic end of the disc. Both angiographic and echocardiographic measured sizes were compared. PDA device size opted was $2 \mathrm{~mm}$ larger than the smallest angiographic diameter. The MPA catheter was exchanged over a support wire with a Mullins sheath (William Cook Europe) of specified size for the selected device. The device was deployed in accordance with the standard procedure. Once the device was deployed echocardiographic evaluation was repeated at 5 minutes to assess the adequacy of closure, residual shunt, turbulence or gradient if any in the left, right pulmonary artery and post ductal aorta. The lower descending thoracic aorta was assessed echocardiographically from an epigastric window for any spectral broadening or turbulence. If a continuous flow was seen through the duct at five minutes, echocardiography was repeated at 10 minute intervals for 30 minutes. If a continuous flow persisted, the device would be upsized by $2 \mathrm{~mm}$. If there was no residual continuous flow the device would be released from the delivery cable without further angiogram and echocardiography repeated before the Mullins sheath used for device deployment was removed. The echocardiographic assessment was repeated at 12 hours, 24 hours (pre-discharge) and 30 days post-procedure.
Patients were discharged the next day. They were followed at 1 month, 3 months, 6 months and yearly. They were assessed for any clinical symptoms, device position by echo, any residual shunt or any other complications. Statistical analyses were performed using SPSS statistics software. All data were analysed as frequencies and percentages or mean and standard deviations and range as appropriate.

\section{RESULTS}

During this period 228 patients were evaluated clinically and echocardiographically for a venous line only approach for PDA closure and 201(88\%) were found suitable. These 201 patients underwent PDA device closure at the Department of Cardiology, Government medical college, Calicut, India.

The mean age was 1 year 6 months (range 6 months to 47 years). The mean weight was $15 \mathrm{~kg}$ (range 5 to $66 \mathrm{~kg}$ ). Females constituted $67.6 \%$ (136 patients), 9 patients ( $4.4 \%$ ) had Down syndrome and 12 (5.9\%) had additional cardiac problems. (Table 1)

PDA Device closure was performed by Amplatzer Duct Occluder type 1 (AD01) device usually. Details of device size and shape used are given in (Table 2). In 123 patients, 6/8 size device was placed (61.2\%), in 32 patients $4 / 6$ size device (15.9\%), 30 patients with $8 / 10$ size device (14.9\%) and a few patients with other size devices.

In our experience, the mean procedure time was $18.3 \mathrm{~min}$ $\pm 3.6 \mathrm{~min}$, the mean fluoroscopic time was $7 \mathrm{~min} \pm 2.1 \mathrm{~min}$ and the mean contrast given was $18 \mathrm{ml} \pm 11 \mathrm{ml}$ (Table 3 ). Two patients had immediate complications. Both had device embolization requiring snaring of the device and were subsequently closed with a $2 \mathrm{~mm}$ larger sized device. One of these had common iliac artery injury during snaring of the device requiring surgical intervention. There was no residual shunt or arch obstruction in any case.

\begin{tabular}{|ccccc|}
\hline & Mean & SD & Minimum & Maximum \\
\hline Height (CM) & 88.4 & 19.3 & 61 & 172 \\
Weight (KG) & 15 & 14.14 & 5 & 66 \\
Age (Years) & 1.5 & 8.43 & 0.5 & 47 \\
\hline \multicolumn{5}{r}{ Table 1. Demographic Data } \\
\hline
\end{tabular}

\begin{tabular}{|ccc|}
\hline & Device Size & Percentage \\
\hline $5 / 4$ & 2 & 1 \\
$4 / 6$ & 32 & 15.9 \\
$6 / 5$ & 1 & 0.5 \\
$6 / 8$ & 123 & 61.2 \\
$8 / 10$ & 30 & 14.9 \\
$10 / 12$ & 5 & 2.5 \\
$14 / 16$ & 2 & 1 \\
$12 / 14$ & 6 & 3 \\
Total & $\mathbf{2 0 1}$ \\
\hline \multicolumn{3}{|c|}{ Table 2. PDA Device Size Used } \\
\hline \multicolumn{3}{|c}{} \\
\hline
\end{tabular}

\begin{tabular}{|ccccc|}
\hline & Mean & SD & Minimum & Maximum \\
\hline Contrast (ML) & 18 & 11 & 7 & 28 \\
Flouro (MIN) & 7.3 & 2.1 & 2.0 & 22 \\
Procedure Time (MIN) & 18.3 & 3.6 & 12 & 40 \\
\hline \multicolumn{5}{r}{ Table 3. Procedure Details } \\
\hline
\end{tabular}

\section{DISCUSSION}

Closure of the PDA through interventional cardiac catheterization is a well-established way of management. ${ }^{11-13}$ This is accomplished mainly using embolization coils 
(William Cook Europe) or Amplatzer duct occluder (ADO) type 1 or less commonly ADO 2(AGA Medical Corporation, Golden Valley, MN). Other devices include Lifetech Duct occluder (ShenZhen Lifetech Scientific Inc), Cocoon PDA device (Vascular Innovation Co Ltd, Thailand) or Occlutech duct occluders (Occlutech International $A B$, Sweden) that have a basic design same as ADO.14-15

The conventional technique involves pre-procedure assessment using echocardiography, and an interventional approach using both femoral arterial and venous access. Arterial access carries an additional procedure and fluoro time, use of a pressure injector with added contrast usage, additional manpower and technique to attain haemostasis and a small but definite risk of access site and vascular complications including limb ischemia more so in small children and infants and added morbidity. A few investigators have described PDA closure without an arterial line. We hereby describe our experience in a larger cohort with some technical differences from the previous reports. ${ }^{10}$

Echocardiography helps in the management of PDA by confirming the diagnosis, estimating the size, assessing the haemodynamics, delineating anatomy of the duct and related great vessels, assessing the need for closure, anatomical feasibility of percutaneous closure, and estimating the route and size of the device for closure. Using a venous line only technique will be based on the echocardiographic assessment of the PDA, for example: if the PDA is very small, it cannot be crossed from the venous side and a retrograde approach should be used. If it is too large, an arterial line will be essential to make sure that using a large device will not compromise the aortic arch. ${ }^{16-17}$ Putting a device in infants with small or no ampulla may cause arch obstruction. Hence, arterial line will be required in those cases. Doing detailed hemodynamic assessment in the cath lab for patients with PDA depends upon the echo findings. PDA without any pulmonary hypertension requires no detailed hemodynamic assessment. PDA is closed via right femoral vein access. Avoiding femoral artery access may prevent the inherent complications resulting from arterial punctures like thrombotic occlusion, access site bleeding, hematoma, longer procedure time and longer admission days in the intensive care unit.

A life-threatening complication can occur due to acute arterial occlusion. PDA device closure via right femoral vein access is possible and safe in skilled operator hands if the echocardiographic assessment of PDA is appropriate. The main benefits of avoiding femoral artery access include less fluoroscopic time, less chance of arterial occlusion and minimum duration of hospital stay. It is necessary to have a correct positioning of the catheter at the PDA ampullaproximal descending aorta using hand injection or power injection for angiographic duct assessment. Angiograms can also be performed through the long delivery sheath. Arterial access may sometimes be needed in small infants with large ductus.

\section{CONCLUSIONS}

PDA device closure via femoral vein access without accompanying arterial access can be done successfully by experienced operators. Detailed clinical, echocardiographic assessment and pre-procedure planning are the key elements for successful PDA device closure via venous route without arterial access. This technique of device closure made the ductal closure very simple with fewer complications and lesser hospital stay. Patients can be discharged the next day after the procedure with a brief period of rest.

\section{Ethical Standards}

Patient/family consent was taken for the procedure including an explanation of the details of the procedure, vascular access as well as possible complications.

Data sharing statement provided by the authors is available with the full text of this article at jemds.com.

Financial or other competing interests: None.

Disclosure forms provided by the authors are available with the full text of this article at jemds.com.

\section{REFERENCES}

[1] Mitchell SC, Korones SB, Berendes HW. Congenital heart disease in 56,109 births. Incidence and natural history. Circulation 1971;43(3):323-32.

[2] Van Der Linde D, Konings EEM, Slager MA, et al. Birth prevalence of congenital heart disease worldwide: a systematic review and meta-analysis. J Am Coll Cardio 2011;58(21):2241-7.

[3] Yarrabolu TR, Rao PS. Transcatheter closure of patent ductus arteriosus. Pediat Therapeut 2012;5(5):1-8.

[4] Rashkind WJ, Cuaso CC. Transcatheter closure of a patent ductus arteriosus: successful use in a $3.5 \mathrm{~kg}$ infant. Pediatric Cardiology 1979;1:3-7.

[5] Webb GD, Smallhorn FJ, Terrien J, et al. Congenital heart disease. In: Libby P, Bonow RO, Mann DL, Zipes DP, eds. Braunwalds' heart disease. $8^{\text {th }}$ edn. Philadelphia: Elsevier 2008: p. 1561.

[6] Condò $M$, Evans $N$, Bellù $R$, et al. Echocardiographic assessment of ductal significance: retrospective comparison of two methods. Arch Dis Child Fetal Neonatal Ed 2012;97(1):F35-8.

[7] Hijazi ZM, Geggel RL Results of anterograde transcatheter closure of patent ductus arteriosus using single or multiple Gianturco coils. Am J Cardiol 1994;74(9):925-9.

[8] Giroud JM, Jacobs JP. Evolution of strategies for management of the patent arterial duct. Cardiol Young 2007;17 Suppl 2:68-74.

[9] Pass RH, Hijazi Z, Hus DT, et al. Multicenter USA amplatzer patent ductus arteriosus occlusion device trial: initial and one-year results. J Am Coll Cardiol 2004;44(3):513-9.

[10] Al-Akhfash AA, Almesned AA, Alqwaiee A. PDA device closure with and without arterial access. Interv Cardiol J 2017;3(2):61.

[11] Kirchenko A, Benson LN, Burrows P, et al. Angiographic classification of the isolated, persistently patent ductus arteriosus and implications for percutaneous catheter occlusion. Am J Cardiol 1989;63(12):877-80. 
[12] Baruteau AE, Hascoët S, Baruteau J, et al. Transcatheter closure of patent ductus arteriosus: past, present and future. Arch Cardiovasc Dis 2014;107(2):122-32.

[13] Liddy S, Oslizlok P, Walsh KP. Comparison of the results of transcatheter closure of patent ductus arteriosus with newer Amplatzer devices. Catheter Cardiovasc Interv 2013;82(2):253-9.

[14] Ghasemi A, Pandya S, Reddy SV, et al. Trans-catheter closure of patent ductus arteriosus-what is the best device? Catheter Cardiovasc Interv 2010;76(5):687-95.

[15] Boehm W, Emmel M, Sreeram N. The Amplatzer duct occluder for PDA closure: indications, technique of implantation and clinical outcome. Images Paediatr Cardiol 2007;9(2):16-26.

[16] Tworetzky W, McElhinney DB, Brook MM, et al. Echocardiographic diagnosis alone for the complete repair of major congenital heart defects. J Am Coll Cardiol 1999;33(1):228-33.

[17] Han BK, Lesser AM, Vezmar M, et al. Cardiovascular imaging trends in congenital heart disease: a single centre experience. J Cardiovasc Comput Tomogr 2013;7(6):361-6. 